\title{
A CONTRIBUIÇÃO DO TERCEIRO SETOR COMO PRESTADOR DE SERVIÇOS PÚBLICOS
}

\section{THE CONTRIBUTION OF THE THIRD SECTOR AS A PUBLIC SERVICE PROVIDER}

\author{
${ }^{1}$ Bruno Valverde Chahaira \\ ${ }^{2}$ Renata Cristina de Oliveira Santos Aoki
}

\section{RESUMO}

Este trabalho aborda a responsabilidade do Terceiro Setor como prestador de serviços públicos. Faz uma reflexão sobre a atuação desse Setor como contributo estatal e analisa sua atuação em atividades empresariais. Para compreender seu funcionamento, apresenta a sociedade civil nesse contexto, primeiro salvaguardando os seus direitos, e segundo, como partícipe do modelo de Estado condizente com o ideal da eficiência e da descentralização econômica; daí, a parceria público-privada. Desse modo, a investigação procura conferir se os serviços prestados pelo Terceiro Setor são eficientes e menos onerosos, o que legitimaria sua parceria com a administração pública. A metodologia utilizada foi bibliográfico-qualitativa.

PALAVRAS-CHAVE: Terceiro Setor, Responsabilidade Social, Estado Mínimo, Princípio da Eficiência, Sociedade Civil

\begin{abstract}
This paper addresses the responsibility of the Third Sector as a provider of public services. Reflects on the performance of this Sector as a state contribution and analyzes its performance in business activities. In order to understand its operation, it presents civil society in this context, firstly safeguarding its rights, and secondly, as a participant in the state model that is in keeping with the ideal of efficiency and economic decentralization; Hence the publicprivate partnership. Research therefore seeks to ensure that the services provided by the Third Sector are efficient and less burdensome, which would legitimize its partnership with the public administration. The methodology used was bibliographic-qualitative.
\end{abstract}

KEY WORDS: Third Sector, Social Responsibility, Minimum State, Principle of Efficiency, Civil Society

\footnotetext{
${ }^{1}$ Mestre em Direito Negocial. Doutor em Direito Constitucional pela Faculdade Autônoma de Direito de São Paulo - FADISP, São Paulo, SP, (Brasil). Advogado. Professor da Universidade Federal de Rondônia - UNIR, Rondônia, RO, (Brasil).E-mail: professorbrunodireito@gmail.com

${ }^{2}$ Mestre em Direito pela Escola Paulista de Direito de São Paulo - EPD, São Paulo, SP, (Brasil). Doutoranda em Direito Constitucional. Advogada. E-mail.: renatasantosaoki@gmail.com.
} 


\section{INTRODUÇÃO}

O Brasil passou nos últimos anos por diversas mudanças na legislação constitucional e infraconstitucional que pudessem contribuir para repensar o papel do Estado na economia brasileira. Tais modificações vieram ao encontro da redução das atribuições estatais, na tentativa de desafogar a máquina público-administrativa, optando, assim, por um Estado mais eficiente do que burocrático, um Estado mínimo, modelo defendido na conhecida Reforma Gerencial.

A Reforma Gerencial caracterizou-se pela privatização de serviços de natureza essencialmente pública para particulares, originando dessa natureza o denominado Terceiro Setor. Fala-se em Terceiro Setor, uma vez que, este funciona como ente de contribuição à atuação do Estado (primeiro setor), e do mercado (segundo setor), a eles se contrapondo e complementando.

Ao Terceiro Setor, que é formado pelas Organizações Sociais (OS), Organizações da Sociedade Civil de Interesse Público (Oscip), Organizações Não Governamentais (ONGs) e serviços sociais autônomos, foram delegadas as atribuições de natureza predominantemente pública, passando este setor a ser responsabilizado pela prestação eficiente de tais serviços.

Nesse diapasão, faz-se necessário questionar se a atuação do Terceiro Setor cumpre com a responsabilidade social, que visa solidificar a prestação de serviços públicos e a exploração de atividade econômica a toda a coletividade, mas primando pela participação social, eficiência e economicidade.

Nessa seara, cumpre investigar se a atuação desse Setor, principalmente, no que se refere à responsabilidade social ao exercício pleno das atividades econômicas, é cumprida com eficiência e eficácia, ou seja, de modo satisfatório que venha a contribuir com os desafios que o Direito Empresarial enfrenta sob esses aspectos, seja de cunho constitucional, seja fiscal. Ainda, se o Terceiro Setor colabora para a ressignificação da máxima na prestação de serviços dos direitos sociais, como formulados na Constituição Federal de 1988.

Para tanto, foi realizada pesquisa de ordem bibliográfica, tendo a problemática sido respondida por meio da utilização do método hipotético-dedutivo.

\section{A ORGANIZAÇÃO DA SOCIEDADE POLÍTICA E DO ESTADO}

Segundo Louis Althusser (1987, pp. 45-46), na sua obra Aparelhos Ideológicos do Estado, muitas vezes o domínio do Estado lhe escapa, porque está "para além do Direito". O 
que isso significa é que o Estado, projetado no bojo da classe dominante, não é público, nem privado; é, "pelo contrário, a condição de toda a distinção entre público e privado".

Complementa explicitando:

Podemos dizer a mesma coisa partindo agora dos nossos "Aparelhos Ideológicos do Estado". Pouco importa que as instituições que os realizam sejam "públicas" ou "privadas". O que importa é o seu funcionamento. Instituições privadas podem perfeitamente funcionar como Aparelhos Ideológicos do Estado.

O Estado subjaz da sociedade, como consequência de um anseio por se organizar e buscar, conjuntamente, o bem comum. Pode se considerar, assim, que o Estado é uma sociedade natural, uma vez que é da natureza do homem viver em sociedade. Nas palavras de Dabin (1939, pp. 90-99):

Chegou um momento em que os homens sentiram o desejo, vago e indeterminado, de um bem que ultrapassa o seu particular e imediato e que ao mesmo tempo fosse capaz de garanti-lo e promovê-lo. Esse bem é o bem comum ou bem público, e consiste num regime de ordem, de coordenação de esforços e intercooperação organizada. Por isso o homem se deu conta de que o meio de realizar tal regime era a reunião de todos em um grupo específico, tendo por finalidade o bem público. Assim, a causa primária da sociedade política reside na natureza humana, racional e perceptível. No entanto, a tendência deve tornar-se um ato; é a natureza que impele o homem a instituir a sociedade política, mas foi a vontade do homem que instituiu as diversas sociedades políticas de outrora e de hoje. O instituto natural não era suficiente, foi preciso a arte humana. 
Para Kant ${ }^{3}$, o Estado encontra legitimidade em um contrato coletivo por meio do qual o povo renuncia à sua liberdade como forma de possibilitar o convívio em sociedade. De acordo com o ideal de Kant, a respeito do conceito e da origem do Estado, que em alguns pontos se aproxima de uma releitura do pensamento rousseauniano ${ }^{4}$, é o poder político que possibilita a criação da figura estatal, o que se dá por meio de um acordo de vontades coletivas. É, então, um contrato social que legitima a existência dessa ficção que se instrumentaliza e organiza a sociedade, com fins de buscar o bem público.

Pode-se entender, assim, que o Estado, com todos os seus aparatos, não passa de uma ficção estruturada, um artifício que se originou da necessidade inerente do ser humano de viver em uma coletividade organizada. A distinção entre a figura soberana do Estado e todas as outras ficções da sociedade civil é a soberania propriamente dita. O Estado caracteriza-se por ser, justamente, possuidor único de imperium $^{5}$, tendo a prerrogativa de, alegando o bem comum e o interesse social, fazer sua vontade se sobrepor à de seus administrados.

Para Dallari (2016, p. 57), "são sociedades políticas todas aquelas que, visando criar condições para a consecução dos fins particulares de seus membros, ocupam-se da totalidade das ações humanas, coordenando-as em razão de um fim comum”. Nessa direção, a sociedade se orientou à constituição da família, contudo, a capacidade da família de influir e condicionar a sociedade como um todo foi aos poucos perdendo força, dando poder a outra sociedade política maior (DALLARI, 2016) que pudesse ampliar o raio de atuação e de influência: o Estado. Aqui se encontra a primeira noção de Estado: é uma sociedade política (2016, p. 58, grifo do autor). Por isso, ao Estado cabe buscar o bem comum, o interesse público, e é nessa busca que o homem vem, através do tempo, modificando a estrutura estatal. A noção de

\footnotetext{
${ }^{3} \mathrm{O}$ ato pelo qual um povo se constitui num Estado é o contrato original. A se expressar rigorosamente, o contrato original é somente a ideia desse ato, com referência ao qual exclusivamente podemos pensar na legitimidade de um Estado. De acordo com o contrato original, todos (omnes et singuli) no seio de um povo renunciam à sua liberdade externa para reassumi-la imediatamente como membros de uma coisa pública, ou seja, de um povo considerado como um Estado (universi) e não se pode dizer: o ser humano num Estado sacrificou parte de sua liberdade externa inata a favor de um fim, mas, ao contrário, que ele renunciou inteiramente à sua liberdade selvagem e sem lei para se ver com sua liberdade toda não reduzida numa dependência às leis, ou seja, numa condição jurídica, uma vez que esta dependência surge de sua própria vontade legisladora. (KANT, Immanuel. A Fundamentação da Metafísica de Direito. A doutrina universal do Direito, p. 158.)

${ }^{4}$ A problemática de Rousseau se concentrava em preservar a liberdade natural do homem e ao mesmo tempo garantir a segurança e o bem-estar da vida em sociedade. Para tanto, elaborou a teoria do contrato social, por meio do qual prevaleceria a soberania da sociedade, a soberania política da vontade coletiva. Rousseau acreditava que seria preciso instituir a justiça e a paz para submeter igualmente o poderoso e o fraco, buscando a concórdia eterna entre as pessoas que viviam em sociedade.

${ }^{5}$ Entende-se poder de imperium como o poder dominante e típico dos Estados soberanos, exercido de maneira imperativa, não existindo outra forma de poder que concorra com este. É o poder originário que legitima a elaboração e aplicação de leis, diante de um determinado povo, nos limites de um determinado território.
}

Revista Brasileira de Direito Empresarial -le-SSN: 2526-0235| Curitiba | v. 2 | n. 2 | p. 222- 242 | Jul/Dez. 2016. 
Estado é permanente, mas não imutável; não existe sociedade sem Estado, mas a forma com que o Estado atua e regula a realidade social, contudo, se modifica em favor da vontade humana.

Segundo Paulo Bonavides (2016, p. 3), não há nada mais difícil de compelir de imediato e de modo satisfatório que o conceito da palavra "sociedade". Nos termos de Talcott Parsons, sociólogo americano, "a palavra mais genérica que existe para referir todo o complexo de relações do homem com seus semelhantes" é sociedade.

O termo Estado advém do substantivo latino status, relaciona-se com o verbo stare, que significa "estar firme"; portanto, a ideia de "estabilidade". Daí ser designado o conceito para sociedade política, estabilizado por um senhor soberano que o controla e orienta os demais senhores. Definição empregada atualmente: "Uma instituição organizada política, social e juridicamente ocupa um território definido e, na maioria das vezes, sua lei maior é uma Constituição escrita". (CICCO, GONZAGA, 2012, p. 45)

$\mathrm{Na}$ concepção filosófica, Hegel era categórico ao mencionar que muito já se havia discutido sobre a antítese entre moral e política e sobre a exigência de a segunda conformar-se à primeira. Para o filósofo, o Estado era como a "realidade da ideia moral", a "substância ética consciente de si mesma", a "manifestação da divindade" (BONAVIDES, 2016, p. 66). Aqui, o Estado tem um direito diferente do bem do indivíduo; nas palavras de Hegel outra coisa não é do que a reiteração do princípio de Niccolò Maquiavel (1469-1527). O que Hegel chama de existência do Estado outra coisa não é senão a realidade efetiva de Maquiavel.

Segundo Bonavides (2016, p. 68):

O Estado, pela origem e pela essência, não passa daquela "instituição social, que um grupo vitorioso impôs a um grupo vencido, com o único fim de organizar o domínio do primeiro sobre o segundo e resguardar-se contra rebeliões intestinas e agressões estrangeiras (FRANZ OPPENHEIMER, Der Staat, p. 5).

Reinhold Zippelius preleciona que a Sociologia só é capaz de compreender adequadamente a "realidade do Estado se também levar em conta o fato de o comportamento humano ser orientado por um sentido e, em especial, a circunstância de a ação humana ser seguida também por normas" (2016, p. 39). Por isso, os modelos de Estado podem causar 
reflexos na sociedade, pois, os valores da máxima de ação do Estado são fatores efetivos dos acontecimentos sociais. Sobre isso, aponta que é necessária "uma ordem normativa", a qual "objetiva com um plano de orientação normativo e intersubjetivo, para coordenar a conduta dos Homens, transformando-o naquela estrutura de condutas a que chamamos comunidade" (p. 40), ou sociedade política de fato e de direito.

Cabe dizer, o Estado antigo, o medieval, o que encontrou seus baluartes nos princípios da Revolução Francesa, o Estado Liberal, o Máximo Keynesianista e aquele de natureza Neoliberal, todos foram, em seu tempo, formas de representação da dinâmica social e passaram por mudanças para adaptar a sua estrutura e forma de atuação às necessidades da socialização.

A forma de atuação do Estado, em qualquer tempo, traz consequências diretas no regime jurídico-social. Observa-se que, no momento de sua formação, o Estado tratou de organizar a sociedade e dividir as esferas de atuação do Direito. Segundo a atribuição clássica de Jean Domat (1829, p. 2), as leis, em relação ao seu conteúdo, se dividiam em públicas e civis. Tal era a separação e independência das referidas leis, que o Direito Civil era tido como "Constituição Privada", ou seja, lei máxima na regulação da vida do indivíduo e administração de seu patrimônio ao passo que a Constituição pública, propriamente dita, tratava da relação entre Estado e particular.

Tal dicotomia se firmava como reflexo do Estado liberal, e com a eventual intensificação da atuação estatal na sociedade, tornou-se obsoleta. Não se podia mais falar em Constituições públicas e privadas, mas sim, em matéria constitucional - ou seja, o Estado influenciando diretamente a vida do particular, por meio de uma "publicização" do Direito Civil, uma das características que propiciaram o surgimento do Welfare State.

A influência da atuação do Estado no ordenamento jurídico pode ser observada, ainda, na promulgação de Constituições dirigentes, que se classificam por ter em seu bojo normas programáticas, o que é um resultado claro do recente surgimento do Estado Social.

\section{A SObERANIA NÃO RESIDE NO ESTADO, MAS SIM, NA POPUlAÇÃO: OS PENSAMENTOS LIBERAIS}


O entendimento de Locke ${ }^{6}$ inspirou o pensamento Liberal, servindo como base para toda a transformação estatal que estava prestes a surgir.

Se, por um lado, Locke foi o responsável por desenvolver o liberalismo político, temse na figura de Adam Smith o grande nome por trás do liberalismo econômico, defendido em sua obra de 1777, A Riqueza das Nações. Para Smith, o Estado deveria ser omisso em relação a toda atividade econômica, uma vez que o mercado se autorregularia conforme a teoria que depois ficou conhecida como "mão invisível".

Embebida pelas teorias liberais de Locke e Smith, a Revolução Francesa de 1789 veio como uma resposta da burguesia às restrições infringidas pelas classes dominantes, quais sejam, monarquia e clero, que impunham durante todo o período da Idade Média uma política de estamentos sociais.

Para tanto, a camada social comandada pelos burgueses, desejosos de possuir poder político, e também de aumentar o lucro nas transações mercantis, encontrou num pensamento privatista os alicerces para atingir o que tanto almejavam: uma concepção político-social que contrapusesse o ideal do Estado Absoluto. E, então, a revolução eclodiu. Nas palavras de Souza (2008, p. 21):

A revolução de 1789 instaura o liberalismo individualista no nível institucional do Estado, limitando a atuação absolutista que dominou a Idade Média. O fundamento político aparente da Revolução era o alcance da certeza jurídica. De poder garantir com firmeza os direitos do homem e, para tanto, era necessária a instauração da liberdade civil.

Mudava-se, assim, o núcleo de todo entendimento acerca da sociedade da época. Saía do centro do pensamento aquele Estado centralizador (antigo), para o modelo moderno, e buscava-se analisar suas influências pela perspectiva individualista. Considera-se que a ordem social, a partir desse momento histórico, passou a ser regida pelos valores do indivíduo.

\footnotetext{
${ }^{6}$ John Locke (1632-1704), filósofo inglês, considerado um dos grandes responsáveis por movimentos como o empirismo e o iluminismo. Locke somava voz ao grupo de autores da época que questionavam o chamado poder divino, concedido ao monarca soberano e fundamento do Estado Absolutista. Segundo Locke, a soberania não reside no Estado, mas sim na população, de onde deveria provir todo poder político. Sua tese também se consubstanciava na teoria da separação do Poderes, que deveriam ser divididos em Executivo, Judiciário e Legislativo.
}

Revista Brasileira de Direito Empresarial -le-SSN: 2526-0235| Curitiba | v. 2 | n. 2 | p. 222 - 242 | Jul/Dez. 2016. 
Começa-se a falar em liberdade e igualdade civis, propriedade privada, no surgimento de uma sociedade fraterna, hegemônica e organizada horizontalmente; entra-se na era do Liberalismo.

Em apertada síntese, a teoria do Liberalismo defendia os fins limitados do Estado. Dito de outra forma, caberia ao Estado reduzir ao máximo suas atividades, principalmente as econômicas, funcionando apenas como vigilante da ordem social. Deveria o Estado agir apenas sob a função de Estado-polícia, sendo vedada qualquer iniciativa em matéria econômica. O Estado liberal sobreviveu até meados do século XX, quando acabou por ser substituído pelo dito Estado Social.

\subsection{O ESTADO SOCIAL COMO CONTRAPONTO DO ANTIGO LIBERALISMO}

O Estado Social teve como cerne o entendimento de que cabe ao Estado atuar como agente de desenvolvimento, promovendo e regulamentando a vida, a saúde, a economia e a política. O grande responsável por difundir a Teoria do Estado Social, ou como também é chamado Welfare State, foi Keynes ${ }^{7}$, por observar que a "mão invisível" não era apta a resolver os anseios da sociedade, como acreditavam os pensadores liberais. O Estado social popularizou-se com as crises econômicas pelas quais passou o Estado moderno, como a queda da Bolsa de Nova York, em $1929^{8}$, e a situação da Europa pós-Guerra.

A ideia do Estado social, no entanto, é mais antiga, surgindo num primeiro momento como uma crítica ao Liberalismo político e, nitidamente atrelado, ao socialismo, como bem

\footnotetext{
7 John Maynard Keynes foi um economista britânico, cuja teoria teve grande influência na macroeconomia moderna. Keynes defendia uma política econômica de Estado intervencionista, ou Estado de Bem-Estar Social, como também ficou conhecida, segundo a qual cabia aos governos usar medidas fiscais e monetárias para repelir os efeitos adversos dos ciclos econômicos.

8 Durante a Primeira Guerra Mundial, a economia norte-americana estava em pleno desenvolvimento. As indústrias dos Estados Unidos produziam e exportavam em grandes quantidades, principalmente, para os países europeus. Com o término da Guerra, o quadro não mudou, uma vez que os países europeus, voltados para a reconstrução das indústrias e cidades, necessitavam manter suas importações, principalmente dos EUA. Contudo, a partir da década de 1920, a situação começou a mudar. Drasticamente: os países, já reconstruídos, não mais necessitavam importar dos Estados Unidos como antes, gerando assim um estoque de produtos norte-americanos que não conseguiam ser vendidos. Fato é que essas empresas, que não mais vendiam como antes, possuíam ações significativas na Bolsa de Valores norte-americana, nas quais milhares de cidadãos desse país tinham investido. $\mathrm{O}$ que se observou foi o processo gradual de desvalorização das ações dessas empresas e a correria da população para vender tais ações. $\mathrm{O}$ efeito foi devastador, pois as ações se desvalorizaram fortemente em poucos dias. O número de falências de empresas foi enorme e o desemprego atingiu quase $30 \%$ dos trabalhadores. A crise, também conhecida como "A Grande Depressão", foi a maior de toda a história dos Estados Unidos. Como nessa época, diversos países do mundo mantinham relações comerciais com os EUA, e a crise acabou se espalhando por quase todos os continentes, como um verdadeiro efeito dominó.
}

Revista Brasileira de Direito Empresarial -le-SSN: 2526-0235| Curitiba | v. 2 | n. 2 | p. 222-242 | Jul/Dez. 2016. 
observa Bonavides (2004, p. 166): “A revolução capitalista tivera em Smith o teórico que a legitimara no campo econômico. Mas em Marx, e somente em Marx, encontrou o seu primeiro e autêntico refutador" "9. Tal fato justifica-se em razão de todo o pensamento marxista iniciar com a crítica, com uma revolta para com os moldes da economia e da política da época.

Muito do trabalho de Marx, todavia, pode ser compreendido como uma releitura do pensamento rousseauniano: ambos são negativistas em relação à longevidade do sistema capitalista; este defendia um socialismo utópico, enquanto aquele o chamado socialismo científico. No liberalismo, a reação era da burguesia capitalista e no marxismo era a classe operária que protestava.

Faz-se mister o comentário de que o Estado Social veio com o sentido se subverter, de reestruturar as instituições sociais da Época. Rousseau encontrava na Democracia a conciliação das classes, um verdadeiro acordo de energias humanas que possibilitaria a busca por um bem comum a todos.

Acerca do Estado Social, preceitua Bonavides (2004, p. 184):

O Estado Social representa efetivamente uma transformação superestrutural por que passou o antigo Estado Liberal. Seus matizes são riquíssimos e diversos. Mas algo no Ocidente o distingue, desde as bases do Estado proletário, que o socialismo marxista intenta implantar: é que ele conserva sua adesão à ordem capitalista, princípio cardeal a que não renuncia. Daí compadecer-se que o Estado Social no capitalismo com os mais variados sistemas de organização política, cujo programa não importe modificações fundamentais de certos postulados econômicos e sociais.

Tal entendimento é deveras importante, pois, apesar de o Estado Social ter suas bases no pensamento marxista, não é objeto de discussão de sua doutrina os sistemas capitalistas e

\footnotetext{
${ }^{9}$ Rousseau deu à democracia moderna sua teoria pura. Marx emprestou ao socialismo a feição científica de que carecia, liberando-o das velhas utopias, comuns a todos os predecessores. [...] O Marxismo começa com a crítica. A democracia de Rousseau teve, também, como ponto de partida, uma análise, na qual o filósofo decompôs a sociedade de seu tempo, sociedade sabidamente medieval, com a herança sobrevivente de feudos e corporações, já incompatível com as bases autoritárias e nacionais do Estado moderno; já em manifesta contradição com o sistema capitalista. (BONAVIDES, Op. Cit., 2004, p. 166)
}

Revista Brasileira de Direito Empresarial -le-SSN: 2526-0235| Curitiba | v. 2 | n. 2 | p. 222-242 | Jul/Dez. 2016. 
socialistas. Assim, pode-se observar no curso da História a Alemanha nazista, a Itália fascista, a Espanha franquista, todos adotando a configuração de um Estado Social, o que não impediu a Inglaterra de Churchill, os Estados Unidos e a França também o fizessem (BUSTILLOS, 2001, p. 1). ${ }^{10}$

\subsection{DO ESTADO DE BEM-ESTAR SOCIAL AO MODELO DO NEOLIBERALISMO}

Com a existência de crises econômicas, começaram a surgir teorias a respeito de um Estado que atuasse diretamente na economia, que, com seu amparo, esta economia se sairia melhor. Este era o espírito da doutrina do Estado Social que, de fato, garantiu aos Estados que a adotaram uma recuperação na economia, mas ao passo que se recuperaram, esta não conquistou avanços, simplesmente estagnação. Por volta da década de 1970, observou-se a necessidade de se "reviver" o liberalismo, mas com uma forma mais adequada para o tempo que estava surgindo. Com isso, surgiu o modelo conhecido por neoliberalismo. O modelo teve como um de seus idealizadores o economista Milton Friedman, defensor da teoria monetarista, na Universidade de Chicago.

Como tudo que se faz é passível de críticas, a doutrina neoliberal também foi objeto de entendimentos controversos que diziam que o sistema iria unicamente favorecer as grandes empresas, e estas prejudicariam os menos favorecidos. Os países pobres e os em desenvolvimento sofreriam com baixos salários, altos índices de desemprego e desigualdade social.

O primeiro chefe de Estado a adotar o modelo neoliberal foi a primeira-ministra do Reino Unido Margaret Thatcher, que o implantou em seu mandato, de 1979 a 1990. Nos Estados Unidos, alguns de seus presidentes o utilizaram como modelo, tais como Ronald Reagan, George Bush e seu filho George W. Bush, em seus respectivos mandatos. No Brasil foi adotado pelo ex-presidente Fernando Collor de Melo, no período de 1990 a 1992,

\footnotetext{
${ }^{10}$ A respeito do Estado Social Francês, obtempera Bustillos (BUSTILLOS, Catarina Setúbal. Políticas Sociais Públicas: O Estado-Providência Francês. Revista do BNDS, Rio de Janeiro, V. 8, N. 15, pp. 195-212, JUN. 2001, p.1 ): o Estado-Providência francês caracteriza-se por ser um modelo de proteção social baseado na ideia de redistribuição de recursos pelo Estado (solidariedade nacional) e financiado, majoritariamente, por um sistema de seguridade social por repartição, consolidado a partir de 1945 e com vocação universalista, para fazer frente aos riscos sociais de empobrecimento, velhice e doenças que atingiam os trabalhadores no pós-Guerra e, assim, manter a coesão social. Após 1974, o sistema baseado no pleno emprego começa a enfrentar as dificuldades trazidas por um desemprego estrutural de longa duração e altas taxas, pelo baixo crescimento econômico, pela nova estruturação econômica mundial e por evoluções demográficas internas inevitáveis.
}

Revista Brasileira de Direito Empresarial -le-SSN: 2526-0235| Curitiba | v. 2 | n. 2 | p. 222-242 | Jul/Dez. 2016. 
posteriormente alavancado por Fernando Henrique Cardoso, em um processo que se iniciou em 1995 e se estendeu até 2003.

\section{A REFORMA GERENCIAL: ESTADO MAIS EFICIENTE E SOCIEDADE MAIS ATUANTE NA ECONOMIA}

Há mais de uma década, o ordenamento jurídico vem sendo alvo de modificações a nível constitucional e infraconstitucional, muitas delas com o fim de implantar um modelo de administração gerencial, tendo como primado o ideal da eficiência. Todavia, esse modelo também deve se voltar para a questão da responsabilidade social inerente nos processos administrativos.

Nesse diapasão, promulgou-se em 1998, a Emenda Constitucional nº 19, como forma de legitimar a Reforma Gerencial do Estado brasileiro que tomara contorno no início da década de 1990. O novo modelo de gestão pública inspirado nas teorias neoliberais veio como resposta à manifesta incapacidade do Estado de atuar ativamente nas suas atribuições, contribuindo de forma efetiva na vida social do particular, como previra a Constituição Federal vigente ${ }^{11}$.

O "Estado mínimo", de cunho neoliberal, é o modelo de gerenciamento estatal que preteriu a burocracia em detrimento da eficiência, e, em razão disso, esta se tornou princípio positivado da Administração Pública, com a alteração da referida emenda constitucional, especificamente, no art. 37 da Constituição Federal de 1988. Tal é a leitura do caput referido dispositivo constitucional: “A administração pública direta e indireta de qualquer dos Poderes da União, dos Estados, do Distrito Federal e dos Municípios obedecerá aos princípios de legalidade, impessoalidade, moralidade, publicidade e eficiência...”(Grifo nosso.)

\footnotetext{
${ }^{11}$ No Brasil, a percepção da natureza da crise e, em seguida, da necessidade imperiosa de reformar o Estado ocorreu de forma acidentada e contraditória, em meio ao desenrolar da própria crise. Entre 1979 e 1994 o Brasil viveu um período de estagnação da renda per capita e de alta inflação sem precedentes. Em 1994, finalmente, estabilizaram-se os preços através do Plano Real, criando-se as condições para a retomada do crescimento. A causa fundamental dessa crise econômica foi a crise do Estado - uma crise que ainda não está plenamente superada, apesar de todas as reformas já realizadas. Crise que se desencadeou em 1979, com o segundo choque do petróleo. Crise que se caracteriza pela perda de capacidade do Estado de coordenar o sistema econômico de forma complementar ao mercado. Crise que se define como uma crise fiscal, como uma crise do modo de intervenção do Estado, como uma crise da forma burocrática pela qual o Estado é administrado, e, em um primeiro momento, também como uma crise política. (BRESSER-PEREIRA, Luiz Carlos. Da administração pública burocrática à gerencial. Revista do Serviço Público, 47 (1) janeiro-abril 1996. Trabalho apresentado ao seminário sobre Reforma do Estado na América Latina organizado pelo Ministério da Administração Federal e Reforma do Estado e patrocinado pelo Banco Interamericano de Desenvolvimento. (Brasília, maio de 1996, pp. 2-3)
}

Revista Brasileira de Direito Empresarial -le-SSN: 2526-0235| Curitiba | v. 2 | n. 2 | p. 222-242 | Jul/Dez. 2016. 
Antes de tal modificação legal, não se falava em eficiência, mas na atuação do Estado como legal, impessoal, moral e pública. Com o advento da Reforma Gerencial, o legislador constituído optou por, como já foi dito, diminuir o tamanho e o alcance do Estado, por entender que suas ferramentas de gestão suscitavam morosidade, uma administração com baixa produtividade e, dito de outra forma, ineficiente.

Acerca do princípio da eficiência, analisa-se a sempre válida conceituação de Meirelles (2013, p. 92):

O Dever de eficiência é o que se impõe a todo agente público de realizar suas atribuições com presteza, perfeição e rendimento funcional. É o mais moderno princípio da função administrativa, que já não se contenta em ser desempenhada apenas com legalidade, exigindo resultados positivos para o serviço público e satisfatório atendimento das necessidades da comunidade e de seus membros.

Nessa perspectiva, cabe à Administração Pública, agora gerencial, buscar sempre a aferição de resultados, ampliando a autonomia e reduzindo o controle entre os entes administrativos. Nesse aporte, surge o interesse pelas privatizações.

As privatizações também se deram em decorrência da Reforma Gerencial, como bem observa Bresser-Pereira (2006, p. 2), uma vez que é "uma característica essencial da reforma do Estado brasileira [...] foi a decisão de privatizar as empresas estatais que produzem bens e serviços para o mercado".

A prática de privatizar, prevista no Plano Diretor da Reforma do Aparelho do Estado $^{12}$, consiste em descentralizar serviços de natureza eminentemente pública para pessoas

\footnotetext{
12،"Esse 'Plano Diretor' procura criar condições para a reconstrução da administração pública em bases modernas e racionais. No passado, constituiu grande avanço a implementação de uma administração pública formal, baseada em princípios racional-burocráticos, os quais se contrapunham ao patrimonialismo, ao clientelismo, ao nepotismo, vícios estes que ainda persistem e que precisam ser extirpados. Mas o sistema introduzido, ao limitarse a padrões hierárquicos rígidos e ao concentrar-se no controle dos processos e não dos resultados, revelou-se lento e ineficiente para a magnitude e a complexidade dos desafios que o País passou a enfrentar diante da globalização econômica. A situação agravou-se a partir do início desta década, como resultado de reformas administrativas apressadas, as quais desorganizaram centros decisórios importantes, afetaram a 'memória administrativa', a par de desmantelarem sistemas de produção de informações vitais para o processo decisório governamental." (PRESIDÊNCIA DA REPÚBLICA, 1995, pp. 5-6) O Plano Diretor da Reforma do Aparelho do Estado fine objetivos e estabelece diretrizes para a reforma da administração pública brasileira, instrumento indispensável para consolidar a estabilização e assegurar o crescimento sustentado da economia. Foi elaborado por determinação do presidente Fernando Henrique Cardoso.
} 
jurídicas de direito privado. Essa práxis, que legitimou de forma significativa a teoria do Estado mínimo, consistia, em outras palavras, em terceirizar, não apenas as atividades de apoio, como segurança e limpeza, por exemplo, mas também as atividades sociais aos membros da sociedade civil.

Dessa proposta, surgiu no ordenamento brasileiro a figura das agências reguladoras $^{13}$, espécie do gênero autarquia, que se caracteriza por observar um regime especial e que, como observa Mello (2009) "desfrutariam de uma liberdade maior do que as demais autarquias".

Por último, outra característica inerente ao conceito de Estado gerencial é a celebração de contratos de gestão ${ }^{14}$, o que possibilitou a formação de parcerias públicoprivadas com os chamados entes de cooperação. Como consequência do exposto, é que se pode observar a significante atuação do Terceiro Setor em âmbitos tipicamente públicos.

\subsection{A ATUAÇÃO DO TERCEIRO SETOR NA ESFERA DOS DIREITOS SOCIAIS: A PRERROGATIVA DA RESPONSABILIDADE SOCIAL}

Com o advento das teorias neoliberais, a Reforma Gerencial e a formação de um mercado mais competitivo e capitalista, o Estado precisou rever sua funcionalidade. Com isso, a necessidade de haver cooperadores em algumas das atividades que, sob o regime administrativo anterior, eram de sua competência, uma vez que este já não estava mais

\footnotetext{
${ }^{13}$ Compreende-se que as agências reguladoras (a exemplo da Aneel, Anatel, ANP, ANA, Antaq, ANTT, Ancine e Anac, entre outras), pessoas jurídicas de direito público e integrantes da Administração Indireta, foram criadas por meio do Decreto-Lei $n^{\circ}$ 200/1967, que destacou sua natureza jurídica de autarquia de regime especial. Contudo, apesar de já há muito tempo existir a previsão legal que deu suporte à criação dessa espécie de autarquia de regime especial, as agências reguladoras só surgiram propriamente no seio da Administração Pública com o advento das teorias neoliberais. Pode-se concluir, então, que foi consequência da tentativa iniciada por Fernando Collor de Mello (1990-1992) e continuada e melhorada por Fernando Henrique Cardoso de reestruturar o Estado. Foi no advento do Estado mínimo e, em decorrência, da reforma gerencial, que a máquina estatal percebeu a necessidade de enxugar seu contingente e atuação no setor privado, passando, assim, a privatizar. As privatizações trouxeram como consequência para o Estado o dever de regular a relação entre o trinômio Administração-Serviços concessionários-Administrado. O referido controle é possível de ser feito por meio das agências reguladoras, uma vez que estas se diferem das autarquias simples por possuírem mais autonomia, seja ela financeira, seja administrativa, e por terem legitimidade de atuar com poder de polícia. Por último, faz-se o entendimento de que, mesmo quando a agência reguladora estiver fiscalizando determinada execução de atividade econômica ou prestação de serviço público, sua atuação será guiada pelos princípios da Administração Pública, uma vez que, como dito, o referido instituto integra o núcleo da Administração Indireta.

${ }^{14} \mathrm{O}$ contrato de gestão se encontra regulamentado por diversas leis esparsas. Cumpre comentar, todavia, a previsão no tocante à Emenda Constitucional n ${ }^{\circ} 19$, que, entre outras modificações, deu novo texto ao artigo 37, que dispõe: " $8^{\circ}$ - A autonomia gerencial, orçamentária e financeira dos órgãos e entidades da administração direta e indireta poderá ser ampliada mediante contrato, a ser firmado entre seus administradores e o poder público, que tenha por objeto a fixação de metas de desempenho para o órgão ou entidade [...]"
}

Revista Brasileira de Direito Empresarial -le-SSN: 2526-0235| Curitiba | v. 2 | n. 2 | p. 222- 242 | Jul/Dez. 2016. 
conseguindo atender às demandas de seu território, na questão, principalmente, dos direitos sociais: saúde, educação, moradia, Previdência Social, lazer, cultura etc. Acentuou-se, daí, a propositura da parceria do Estado com o Terceiro Setor, para o qual seriam delegadas funções, as quais, anteriormente, seriam próprias da Administração Pública.

Para se compreender o conceito de Terceiro Setor, segundo preleciona Montaño (2010, p. 182) faz-se mister o entendimento da existência conforme a harmonia de dois outros setores. Nas palavras do autor supracitado, “o 'terceiro setor' refere-se, em contraposição ao 'primeiro setor' (Estado), e o 'segundo'(mercado) [...] à sociedade civil”'.

No que tange ao entendimento acerca do Terceiro Setor, este se ramifica em três: serviços sociais autônomos, Organizações Sociais (OS) e as Organizações da Sociedade Civil de Interesse Público (Oscip). Mesmo com essa divisão, suas estruturas são semelhantes, porque são de cunho privado, atuam em atividades não exclusivas do domínio da administração pública, e por receberem subsídios estão, assim, sujeitas ao controle administrativo. Outra característica dos entes citados é que, apesar de atuarem ao lado do Estado, não integram a Administração Indireta.

No que diz respeito aos serviços sociais autônomos, sistema criado no Brasil, são aqueles que de direito privado foram instituídos pelo poder público, com o fim de levar assistência ao ensino para determinadas classes sociais e profissionais. Para se sustentar, eles recebem, como diz Meirelles (2013, p. 2854): de “dotações orçamentárias ou contribuições parafiscais"; o administrador concede a liberdade para que cumulem incentivos parafiscais na natureza de tributos, uma vez que não recebem subsídios de seus mantenedores.

Característica relevante é que para prestar os referidos serviços, há que se saber quais são eles, porque não são inseridos ou prestados àqueles eminentemente de responsabilidade do Estado, mas os que foram delegados na normativa. Desse modo, as atividades que são de importância aos administrados. Nesse grupo, enquadra-se o conhecido Sistema "S": Sesi, Senac, Sesc, Sesi.

Conforme dito acima, o Terceiro Setor apresenta-se também na forma de Organizações Sociais, que se encontram previstas na lei $\mathrm{n}^{\circ} 9.637 / 1998$, e, segundo o entendimento de Di Pietro (2006, p. 489):

São pessoas jurídicas de direito privado, sem fins lucrativos, instituídas por iniciativa de particulares, para desempenhar serviços 
sociais não exclusivos do Estado, com incentivo e fiscalização pelo Poder Público, mediante vínculo jurídico instituído por meio de contrato de gestão.

Esse modelo de setor, que se expandiu com a Reforma Gerencial, caracteriza-se por: a) ser pessoa jurídica de direito privado; b) sem o intuito de arrecadar lucro; c) deverá ser habilitada diante da administração para que seja declarada como entidade de utilidade pública, uma vez que será declarada por medida provisória; d) sua finalidade será estipulada mediante contrato, no qual este especificará todas suas atribuições e deveres perante a Administração; uma vez que contratada, implicará a fiscalização de um órgão competente, em busca de que seja cumprido o que foi explicitado no contrato.

Ainda neste diapasão, têm-se as Organizações da Sociedade Civil de Interesse Público (Oscip), que têm sua existência garantida por meio da Lei nº 9.790/1999, a qual possibilita a existência de parceria entre o ente privado e o Estado.

Embora se assemelhe ao modelo anterior, elas não se confundem, haja vista que as Oscip se diferem na sua criação, porque emergiram do anseio de substituição dos órgãos de administração direta; ao passo que as Organizações Sociais (OS) se firmam por meio de contrato, tendo em conta a necessidade de se firmarem com termo de parceria. Outra característica que diferencia as OS das Oscip é que a segunda é qualificada por meio de ato vinculado, enquanto a primeira necessita de ato de natureza discricionária.

Também é de grande valia saber que, uma vez enquadrada em um desses modelos, não poderá ter dupla personalidade, assim não se enquadrando nas duas formas.

\section{A TRIPARTIÇÃO “ESTADO-MERCADO-TERCEIRO SETOR” E O ESTIGMA DO CONTRIBUTO SOCIAL}

Tendo compreendido os conceitos básicos acerca do Terceiro Setor, cumpre questionar se sua atuação "lado a lado" com o Estado contribui, de modo responsável, para que este possa alcançar níveis de eficiência, como acreditavam os defensores da teoria do Estado mínimo e do modelo de administração neoliberal.

Uma questão a ser levantada é que, com a retirada do Estado de alguns segmentos econômicos, sua responsabilidade para com o cidadão se encontrava altamente restringida.

Revista Brasileira de Direito Empresarial -le-SSN: 2526-0235| Curitiba | v. 2 | n. 2 | p. 222-242 |

Jul/Dez. 2016. 
Assim, formar-se-ia um verdadeiro "Estado de Mal-Estar" social, no qual a população se encontraria desassistida e à mercê da atuação de entes privados, ao passo que, ao Estado incumbiria apenas o gerenciamento de programas assistenciais.

Nesse sentido, aduz Montaño (2010, p. 489):

As limitações que existiam no padrão anterior de resposta à "questão social" não apenas não são resolvidas pela reestruturação neoliberal, mas em muitos casos são agravadas. Assim: a má distribuição e baixa cobertura dos programas sociais; o caráter predominantemente contratualista (excluindo os não contribuintes); a estratificação de benefícios, reproduzindo as desigualdades; a inexistência de um enfoque redistributivista da política social; a ausência de proteção econômica para o desempregado; um padrão financeiro perverso, insuficiente e regressivo. [...] Essas limitações no novo padrão neoliberal de política social estatal são caracterizadas pela primazia de "programas assistenciais de caráter apenas suplementar e emergencial", “dirigidos apenas para os pobres".

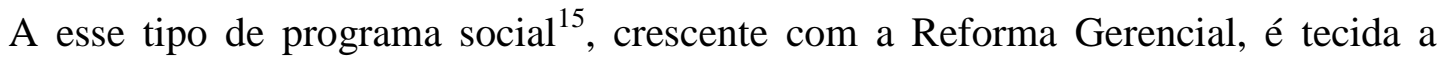
crítica em torno de sua natureza temporária, porque passa a funcionar como um paliativo e, por não possuir o condão de resolver as questões conflitantes sociais, acaba por confirmar, ou ainda aumentar, as desigualdades, porque não dá a resposta necessária aos problemas preexistentes. Graças à sua funcionalidade "paliativa", não há o tempo necessário para que possa se efetivar de modo condizente às reais exigências sociais, atuando, muitas vezes, sem a responsabilidade social que lhe é conferida, principalmente, nas atuações que tratam os

\footnotetext{
${ }^{15}$ O primeiro programa de impacto no Brasil foi o Programa Comunidade Solidária, instituído durante o mandato do presidente Fernando Henrique Cardoso, com a finalidade de combater a fome e as suas causas estruturais, que geram a exclusão social e para garantir a segurança alimentar de todos os brasileiros e brasileiras em três frentes: um conjunto de políticas públicas; a construção participativa de uma Política Nacional de Segurança Alimentar e Nutricional; e um grande mutirão contra a fome, envolvendo as três esferas de governo (federal, estadual e municipal) e todos os ministérios. Com a mesma finalidade surgiu o Programa Fome Zero, maior programa assistencialista na história brasileira. De acordo com dados do site do programa, no Brasil existem 44 milhões de pessoas ameaçadas pela fome. O Programa Fome Zero consiste num conjunto de mais de 30 programas complementares dedicados a combater as causas imediatas e subjacentes da fome e da insegurança alimentar, implementados pelo ou com o apoio do governo federal. Considera-se que esses programas são consequência da Reforma Gerencial e da redução do tamanho do Estado.
} 
direitos sociais: educação, saúde, cultura etc. Pode-se entender, também, que esse tipo de política emergencial perpetua a pobreza e abre campo para a criação de um sistema clientelista, consequentemente, de fórum disperso da responsabilidade social prevista à qualidade de prestação de serviços.

Para tanto, cumpre analisar os direitos atingidos pela esfera privada, através do Terceiro Setor, para que se possa conferir em quais áreas de atuação privada e fiscalizadas pelas agências reguladoras está de fato atuando. Há ainda de se verificar outros empreendimentos na seara empresarial ora investidos pelo Terceiro Setor, como a telefonia e a arrecadação de energia elétrica, por exemplo, tendo a preocupação de averiguar as reais implicações advindas desse mecanismo empresarial, se de fato cumpre com responsabilidade, o que lhe convém na prestação de serviços que seriam destinados ao setor público. Isso serve para acompanhar, seja o crescimento de investimentos do Setor na esfera administrativa, seja a melhoria desse crescimento quanto à eficiência e economicidade. $\mathrm{O}$ que se tem observado quanto a essa questão é que alguns nichos empresariais que o Setor adentrou em substituição à prestação de serviços do Estado ainda engatinham e apresentam várias deficiências na prestação dos referidos serviços públicos.

Noutro giro, cumpre destacar que o Terceiro Setor, na medida em que está, em determinada esfera dissociado da burocracia que marca a Administração Pública, é capaz de atuar na esfera privada - empresarial, portanto - com mais propriedade. Daí porque, percebese que esse Setor representa uma opção à questão dos direitos sociais, máxima do neoconstitucionalismo e dos desafios que caracterizam a pós-modernidade, não obstante enseje ainda em uma evolução à atuação empresarial, seja em âmbito público, seja no privado.

Desta feita, analisar o papel do Terceiro Setor no âmbito empresarial insta pensar na sua atuação empresarial - se com responsabilidade social, que não tem como outra medida se desvencilhar da busca desenfreada pelo lucro, mas sim, ir ao encontro da compatibilização do interesse social e do desenvolvimento econômico do país; porque, além de configurar-se como alternativa para o Estado no saneamento das dificuldades inerentes a alguns setores de prestação de serviços sociais, colabora ao campo do Direito Administrativo e da Gestão Pública, como possibilitador da releitura dos institutos clássicos do Direito Público e Privado.

\section{CONSIDERAÇÕES FINAIS}


O Terceiro Setor, objeto das reformas legais pelas quais a Administração Pública passou, na década de 1990, a destacar a Reforma Gerencial, incita vários debates, de um lado a seu favor, de outro contrário. Questiona-se se o modelo adotado pelo Estado mínimo implica deixar de prestar serviços públicos, como também se a exploração da atividade econômica por parte desse Setor é realizada com responsabilidade, é eficiente como se observa na regra suscitada desde a defesa da Reforma Gerencial, principalmente.

Há, ainda, as incessantes referências sobre os modelos de privatizações propostos na Reforma Gerencial, foco do modelo de Estado neoliberal. Com as privatizações, consequência clara do enxugamento da máquina estatal, alguns dos serviços que eram de natureza exclusivamente pública, em sua maioria serviços essenciais, como a saúde e a educação, por exemplo, foram descentralizados do Estado e passados, de modo sutil ao setor privado, cabendo a este se responsabilizar pela prestação de serviços antes de cunho estatal. Nesse sentido, a necessidade de fiscalizar, orientar, normatizar tais empreendimentos, haja vista que a responsabilidade pelos serviços prestados ao coletivo devem se fincar na eficiência econômica, sem, contudo, desconsiderar a qualidade e o benefício à sociedade e ao Estado. Portanto, cabe aqui a responsabilidade social que servirá também ao exercício da cidadania, seja pelo Setor atuante, seja pela sociedade que receberá seus serviços.

Nesse cenário é que surgem as agências reguladoras, autarquias de regime especial que se caracterizam por ter maior autonomia funcional, cuja finalidade imediata é a fiscalização desses serviços que foram repassados à sociedade civil, ou, em outras palavras, ao denominado Terceiro Setor.

Existe, ainda, o entendimento de que o Estado promoveu o engrandecimento do Terceiro Setor não com os fins de atingir maior eficiência, mas para reduzir suas despesas e construir uma cultura em que a não prestação de serviços públicos pode ser mascarada pela autoculpa construída sob as mazelas sociais. Contudo, tal entendimento não deve ser aceito, uma vez que o Terceiro Setor, agindo com responsabilidade, como um contributo à atividade estatal, pode ser um parceiro de excelência à economia, aos direitos sociais, à coletividade. Compreende-se, então, a existência de uma atuação "lado a lado" com Estado, que, mesmo sendo imbuído de caráter neoliberal, pode permitir o bom gerenciamento da administração pública, primando à eficiência pela burocracia. Afinal, constata-se que o debate acerca da operacionalização do Terceiro Setor é questão fundamental no bojo do Estado Democrático de Direito; assim não fosse, o artigo 170 da CF/88 não o caracterizaria como tal. No entanto, 
para a sua consolidação e legitimação é válido dizer que é a sociedade civil que lhe garante o exercício e/ou atuação, para substituir a atividade estatal (e suas garantias), por isso, a sociedade e o Estado, juntos na formulação e regulamentação do Terceiro Setor, contribuem com o desenvolvimento de uma administração mais eficiente e responsável com as causas sociais. Como consequência, não se pode outorgar que o Terceiro Setor substitua o Estado, assim sendo vedada a delegação por completo ao particular das atribuições estatais. Todavia, admite-se a existência de uma parceria entre Estado e Terceiro Setor para que este aperfeiçoe a prestação de serviços públicos e o exercício de atividade econômica, ao passo que àquele caiba fiscalizar e gerir de maneira eficiente a Administração Pública, tutelando e garantindo aos administrados seus direitos fundamentais previstos pela Carta Constitucional, de modo consciente e responsável, reitera-se.

É nessa seara que o Terceiro Setor é apontado como alternativa à crise de eficiência e eficácia dos serviços públicos prestados ao Estado, consubstanciando-se em instrumento de releitura dos Direitos Público e Privado. Por conseguinte, colaboram os estudos na tentativa de elaborar a epistêmica do Direito Empresarial, e este passe a ser interpretado consoante os aportes neoconstitucionais de tutela aos direitos fundamentais e ao interesse coletivo, ao exercício da cidadania e da organização da sociedade.

\section{REFERÊNCIAS BIBLIOGRÁFICAS}

ALTHUSSER, Louis. Aparelhos Ideológicos de Estado. $3^{\text {a }}$ ed. Rio de Janeiro: Edições Graal, 1987, pp. 45-46.

AZAMBUJA, Darcy. Teoria Geral do Estado. 2a ed. São Paulo: Editora Globo, 2011, p. 171.

BONAVIDES, Paulo. Do Estado Liberal ao Estado Democrático. $5^{\text {a }}$ ed. São Paulo: Malheiros Editores, 2004.

BONAVIDES, Paulo. Do Estado Liberal ao Estado Social. $7^{\text {a }}$ ed. São Paulo: Malheiros, 2006.

Curso de Direito Constitucional. 18. ed. São Paulo: Malheiros, 2006.

Teoria Geral do Estado. 10a ed. rev. ampl.São Paulo: Malheiros Editores, 2015.

Revista Brasileira de Direito Empresarial -le-SSN: 2526-0235| Curitiba | v. 2 | n. 2 | p. 222 - 242 | Jul/Dez. 2016. 
BUSTILlOS, Catarina Setúbal. Políticas Sociais Públicas: O Estado-Providência Francês. Revista do BNDS, Rio De Janeiro, V. 8, N. 15, P. 195-212, JUN. 2001.

CICCO, Cláudio de; GOnZAGA, Álvaro de Azevedo. Teoria Geral do Estado e Ciência Política. 4. Ed. São Paulo: Editora Revista dos Tribunais, 2012.

COUTINHO, Carlos Nelson. El Concepto de Sociedad Civil en Gramsci y la Lucha Ideológica en el Brasil de Hoy. Rio de Janeiro, UFRJ, 2000. Mimeo.

DABIN, Jean. Doctrine Générale de l'État. Paris: Sirey, 1939, pp. 99-90.

DALlaRI, Dalmo de Abreu. Elementos da Teoria Geral do Estado. 33. ed. São Paulo: Saraiva, 2016.

DI PIETRO, Maria Sylvia Zanella. Direito Administrativo. 19 ed. São Paulo: Atlas, 2006 p. 489.

DOMAT, Jean. Le Droit Public, Suite des Lois Civiles dans Leur Ordre Naturel. vol. 3, Oeuvres completes, nouvelle édition revue corrigée, ed. Joseph Remy (Paris: Firmin-Didot, 1829, pp. 1-2.

KANT, Immanuel. A Fundamentação da Metafísica de Direito. A Doutrina Universal do Direito, p. 158.

LASKI, Harold J. Grammaire de la Politique. Paris: Delagrave, 1933, p. 9.

MEIRELLES, Hely Lopes. Direito Administrativo Brasileiro. 39ª ed. São Paulo: Malheiros, 2013.

MELlO, Celso Antonio Bandeira. Curso de Direito Administrativo. 26 ed. São Paulo: Malheiros Editores, 2009.

PEREIRA, Luiz Carlos-Bresser. Da Administração Pública Burocrática à Gerencial. Revista do Serviço Público, 47 (1) janeiro-abril 1996. Trabalho apresentado ao seminário sobre Reforma do Estado na América Latina organizado pelo Ministério da Administração Federal e Reforma do Estado e patrocinado pelo Banco Interamericano de Desenvolvimento (Brasília, maio de 1996). 
Reflexões sobre a Reforma Gerencial de 1995. In Revista do Serviço Público. Ano 50, n. 5, out-dez, 1999.

SOUZA, Rodrigo Trindade de. Função Social do Contrato de Emprego. São Paulo: LTr, 2008, p. 21.

ZIPPELIUS, Reinhold. Teoria Geral do Estado. Tradutores Antônio Francisco de Sousa, António Franco. São Paulo: Saraiva, 2016. 